\title{
Diagnostic and therapeutic challenges in extragonadal yolk sac tumor with hepatoid differentiation: A case report
}

\author{
VANJA ZEREMSKI ${ }^{1}$, CHRISTIAN MAWRIN ${ }^{2}$, THOMAS FISCHER $^{1}$ and ENRICO SCHALK ${ }^{1}$ \\ Departments of ${ }^{1}$ Hematology and Oncology, and ${ }^{2}$ Neuropathology, Medical Center, \\ Otto-von-Guericke University Magdeburg, D-39120 Magdeburg, Germany
}

Received July 14, 2016; Accepted October 13, 2016

DOI: $10.3892 / \operatorname{mco} .2016 .1080$

\begin{abstract}
Yolk sac tumors (YSTs) are rare aggressive tumors, arising most commonly in the gonads and occurring mainly in young adults. We herein report a case of an extragonadal YST with hepatoid differentiation localized in the brain and lung. A 41-year old man presented to our hospital with a generalized seizure. A head computed tomography and magnetic resonance imaging examination revealed a large mass in the left occipital lobe with associated edema. Following complete resection, the histopathological examination revealed that the mass was a highly malignant epithelial tumor with a hepatoid pattern. The serum lactate dehydrogenase and $\alpha$-fetoprotein levels were elevated. Additional diagnostic imaging revealed a lesion in the upper lobe of the right lung, but no other tumor manifestations. Based on the clinical and immunohistochemical characteristics, hepatocellular carcinoma and hepatoid adenocarcinoma were excluded and the diagnosis of extragonadal hepatoid YST was established. A multimodal therapeutic approach (high-dose chemotherapy with autologous stem cell transplantation, radiation and surgery) was applied; however, the patient succumbed to refractory disease 10 months after the diagnosis. Therefore, the diagnosis and treatment of hepatoid YST is an interdisciplinary challenge.
\end{abstract}

\section{Introduction}

Germ cell tumors (GCTs) are the most common malignancies in males aged 15-35 years, whereas only $2-5 \%$ of these tumors arise in extragonadal sites (1). The most common extragonadal localization is the mediastinum, followed by the retroperitoneum, pineal gland and suprasellar region $(2,3)$. GCTs comprise a variety of histologically different types that carry different prognoses. The presence of yolk sac

Correspondence to: Dr Enrico Schalk, Department of Hematology and Oncology, Medical Center, Otto-von-Guericke University Magdeburg, 44 Leipziger Street, D-39120 Magdeburg, Germany E-mail: enrico.schalk@med.ovgu.de

Key words: extragonadal yolk sac tumor, hepatoid differentiation, differential diagnosis, treatment, multidisciplinary elements is associated with a dismal prognosis (4-6) and is found in $30-40 \%$ of GCTs $(1,7)$. Yet pure yolk sac tumors (YSTs) in adult males are rare. We herein report a case of an extragonadal YST with hepatoid differentiation (hepYST), primary localized in the brain and lung.

\section{Case report}

A 41-year old man was admitted to our emergency department with a generalized seizure. No motor or sensory symptoms were present, but there was retrograde amnesia and altered mental status. The physical examination was unremarkable. The patient's past medical history included orchidopexy in childhood.

A head computed tomography (CT) and magnetic resonance imaging (MRI) examination revealed a large mass $(5 \times 3 \mathrm{~cm})$ in the left occipital lobe with associated edema (Fig. 1). The patient underwent total tumor removal via left occipital craniotomy. The postoperative course was complicated by severe transitional hemiparesis.

The histopathological examination of the resected tumor revealed large, eosinophilic cells with round, centrally located nuclei, arranged in cords or trabeculae. The tumor cells focally contained PAS-positive intracytoplasmic and extracytoplasmic hyaline bodies. Immunohistochemically, the tumor cells were diffusely positive for Hep Par-1, glypican-3 and cytokeratin (CK) 8; $\alpha$-fetoprotein (AFP) was focally expressed and $\mathrm{Ki}-67$ staining revealed $80 \%$ positive tumor cell nuclei, indicating a very high proliferation activity (Fig. 2). By contrast, the tumor cells were negative for placental alkaline phosphatase, octamer-binding transcription factor 3/4, CK20, CD30 and c-kit. The immunohistochemical findings were thus consistent with malignant epithelial GCT with a hepatoid pattern.

The serum lactate dehydrogenase (LDH) and AFP levels were markedly elevated (Table I). The serum human chorionic gonadotropin level was within the normal range. Chest CT revealed a lesion sized $2 \times 1 \mathrm{~cm}$ in the upper lobe of the right lung. No other lesions were identified using testicular ultrasound, abdominal CT, liver MRI and gastroscopy.

Taking all laboratory findings into account, the diagnosis of an extragonadal hepYST was considered to be likely.

Initially, the patient underwent two courses of cisplatin, etoposide and ifosfamide (PEI regimen). However, subsequent 
restaging revealed an increase in the serum AFP and LDH levels, as well as an increase in the size of the intracranial lesion; the lung lesion remained stable. Given the refractory disease and unfavorable prognostic characteristics (8), a decision was made to treat the patient with a high-dose salvage chemotherapy protocol according to Kondagunta et al [two courses of paclitaxel and ifosfamide (TI regimen) followed by three courses of high-dose carboplatin and etoposide (CE regimen) plus peripheral blood stem cell support] (9). However, after the first high-dose chemotherapy course, the patient developed hemiparesis. The serum AFP and LDH levels increased and the head CT revealed marked tumor progression. In order to achieve a fast tumor mass reduction, cranial irradiation and surgical removal of the lung tumor were performed. The histopathological examination was consistent with hepYST. High-dose chemotherapy (two remaining high-dose CE courses) was resumed as ultima ratio for disease control.

Unfortunately, despite therapy, subsequent restaging showed an increase in tumor markers, as well as new and multiple lung and liver metastases. Palliative therapy with oral etoposide was administered and the patient succumbed to refractory disease 10 months after the initial diagnosis.

\section{Discussion}

YSTs are rare, aggressive tumors, occurring mainly in young adults, with a peak incidence at 21 years $(10,11)$. YSTs arise most commonly in the gonads, but extragonadal sites of origin are reported in $24 \%$ of the cases (11). The most common localization of YST is the anterior mediastinum, followed by the retroperitoneum and cranium $(2,3)$; exceedingly rare sites, such as the lungs, pancreas, kidney and spinal cord, have also been reported (12-15). Regarding the intracranial manifestations, YSTs are typically located midline in the pineal region or the suprasellar region (3). One case of mixed GCT with extensive yolk sac elements outside the midline (in the frontal lobe) in an adult was also reported (16).

Intracranial YSTs present a unique entity. They may disseminate along the neuroaxis, at the time of diagnosis or early during the course of the disease. However, to the best of our knowledge, a case of intracranial YST with concomitant extracranial manifestation has not been reported thus far. In the case presented herein, the tumor was located in the occipital lobe and lungs. Due to its atypical location and the radiological findings (absence of necrosis, hemorrhage, cysts) (17), the suspected preoperative diagnosis was primary brain tumor rather than GCT. However, the histological examination did not support this diagnosis. Immunohistochemically, the tumor cells expressed Hep Par-1, glypican 3 and AFP; this immunoprofile is compatible with hepatocellular carcinoma (HCC), hepatoid adenocarcinoma (HAC), as well as hepYST (Table II) (10). Hep Par-1 is expressed in normal and neoplastic hepatocytes and has been used to confirm hepatoid differentiation. The degree of staining may correlate with hepatoid differentiation, and a strong Hep Par-1 positivity favors HCC diagnosis, but is found only in a minority of hepYST (18). Glypican 3 and AFP are also quite specific for hepatocellular differentiation and are typically expressed in HCC, HAC and hepYST (18).

The clinical characteristics of our patient made the diagnosis of HCC and HAC highly unlikely, as both those tumors
Table I. Tumor marker levels during the course of the disease.

\begin{tabular}{lcc}
\hline Treatment & AFP $(\mathrm{ng} / \mathrm{ml})^{\mathrm{a}}$ & LDH $(\mu \mathrm{mol} / \mathrm{sec} / \mathrm{l})^{\mathrm{b}}$ \\
\hline Preoperative/naïve & n/a & 7.53 \\
Postoperative & 265 & 3.40 \\
After 1 PEI & 230 & 3.48 \\
After 2 PEI & 410 & 4.53 \\
After 1 TI & 332 & 12.76 \\
After 2 TI & 262 & 3.37 \\
After 1 CE + autoTx & 614 & 4.08 \\
After radiation and & 397 & 6.43 \\
lung resection & & \\
After 2 CE + autoTx & 559 & 8.62
\end{tabular}

${ }^{\mathrm{a}} \mathrm{AFP}$ reference value, $<7 \mathrm{ng} / \mathrm{ml}$; ${ }^{\mathrm{b}} \mathrm{LDH}$ reference value, 2.25-3.75 $\mu \mathrm{mol} / \mathrm{sec} / 1$.AFP, $\alpha$ fetoprotein; $\mathrm{LDH}$, lactate dehydrogenase; n/a, not available; PEI, cisplatin/etoposide/ifosfamide; TI, paclitaxel/ifosfamide; CE, carboplatin/etoposide; autoTx, autologous stem cell transplantation.

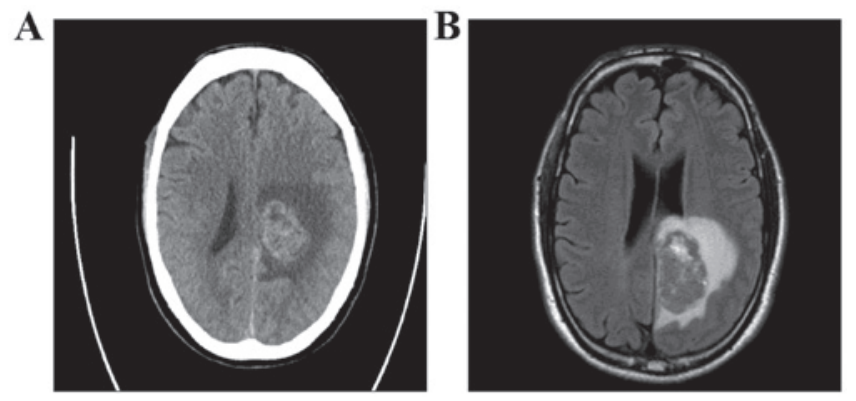

Figure 1. Radiological examination. Preoperative (A) Computed tomography and (B) magnetic resonance imaging with contrast enhancement of the brain, showing a lesion sized $5 \times 3 \mathrm{~cm}$ in the left occipital lobe, with associated edema.

predominantly affect older males $(19,20)$. Brain metastases at the time of diagnosis are extremely rare $(<1 \%$ in $\mathrm{HCC}$ and not reported in HAC) $(19,20)$. Most importantly, the absence of a primary tumor in the liver or other gastrointestinal organs on initial presentation strongly argued against HCC or HAC. Based on all the characteristics mentioned and discussed above, hepYST was the most likely diagnosis.

hepYSTs are exceedingly rare, with only 32 reported cases in the English medical literature to date (10). The majority of these tumors arise from the ovary, whereas only single cases with an extraovarian origin are described. In adult males, cases of sole mediastinal and testicular hepYSTs are reported $(21,22)$.

The treatment of YSTs may be challenging. Standard care is similar to that for other types of non-germinoma GCT and includes platinum-based chemotherapy protocols, followed by surgical resection of the residual tumor or radiation (23). The most widely adopted regimens are PEI and bleomycin, etoposide and cisplatin $(2,24)$. In our case, due to tumor location in the brain and lung, PEI was selected. Unfortunately, the patient had already experienced progression during therapy. 
Table II. Characteristics of immunohistochemical staining of hepatocellular carcinoma, hepatoid adenocarcinoma and hepatoid yolk sac tumor.

\begin{tabular}{|c|c|c|c|}
\hline Staining & $\mathrm{HCC}$ & HAC & hepYST \\
\hline AFP & + & + & + \\
\hline \multirow[t]{2}{*}{ pCEA } & + & + & + \\
\hline & $\begin{array}{l}\text { Canalicular } \\
\text { pattern }\end{array}$ & $\begin{array}{l}\text { Diffuse membranous } \\
\text { or canalicular patterns }\end{array}$ & \\
\hline Glypican 3 & + & ++ & + \\
\hline SALL4 & $\begin{array}{c}+ \\
\text { (Cut-off: } 7 \% \text { in } \\
25 \% \text { of cells) }\end{array}$ & + & $\begin{array}{c}++ \\
\text { (Cut-off: } 100 \% \text { in } \\
25 \% \text { of cells) }\end{array}$ \\
\hline Hep Parl & + & + & - \\
\hline CK 7/CK20 & $-/-$ & + or $-/+$ or - & - \\
\hline
\end{tabular}

HCC, hepatocellular carcinoma; HAC, hepatoid adenocarcinoma; hepYST, hepatoid yolk sac tumor; AFP, $\alpha$-fetoprotein; pCEA, polyclonal carcinoembryonic antigen; SALL4, SAL-like protein 4; Hep Par-1, hepatocyte paraffin 1; CK, cytokeratin.
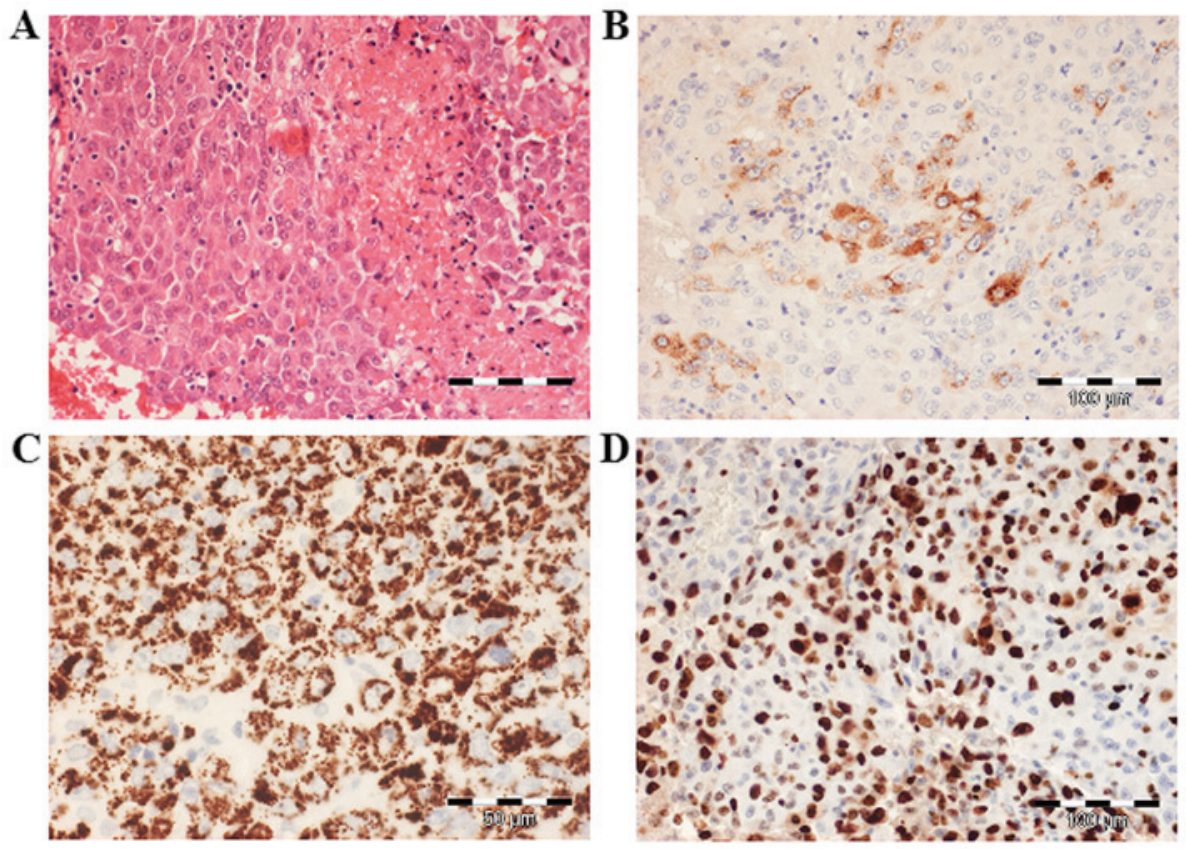

Figure 2. Histopathological examination. (A) Hematoxylin and eosin staining demonstrated a cellular tumor with polygonal cells and tumor necrosis. (B) Focal expression of $\alpha$-fetoprotein. (C) Diffuse and strong immunopositivity for Hep Par-1. (D) Ki-67 staining revealed an extremely high proliferation rate. Magnification, $\mathrm{x} 200$ in all panels.

Subsequent salvage high-dose chemotherapy, including tumor resection and radiation, did not achieve disease control and the patient succumbed to the disease 10 months after diagnosis. Similar survival rates were reported by Moran et al (21). In a case series of 4 patients with mediastinal hepYST, 3 patients succumbed to the disease within 1 year after the initial diagnosis. A large series with 788 YST patients reported sustainably better survival rates: The 5-year overall survival was $55 \%$ (54\% for mediastinal and 60\% for retroperitoneal YSTs) (11). Unfortunately, survival rates according to histological YST subtypes are not available, which poses the question whether histological YST subtype, i.e., hepatoid differentiation, affects survival. Goebel et al (Proc ASCO 22: abs. 1842, 2003) reported an association of hepYST with a higher risk of relapse following initial treatment, as supported by our case.

In conclusion, hepYST is a rare differential diagnosis in the spectrum of brain tumors, including metastases, with poor prognosis. Due to the rarity of these tumors, clear therapeutic recommendations and survival data are currently not available. Thus, treatment of hepYST is considered to be an interdisciplinary challenge.

\section{Acknowledgements}

We would like to thank Dr Guido Reifenberger, Department of Neuropathology, Heinrich Heine University, Düsseldorf, 
Germany and Dr Ivo Leuschner, Department of Pediatric Pathology, Kiel Pediatric Tumor Registry, University Hospital of Schleswig-Holstein, Kiel, Germany, for the contribution to the discussion of the histological findings.

\section{References}

1. Stang A, Trabert B, Wentzensen N, Cook MB, Rusner C, Oosterhuis JW and McGlynn KA: Gonadal and extragonadal germ cell tumors in the United States, 1973-2007. Int J Androl 35: 616-625, 2012.

2. Albany $\mathrm{C}$ and Einhorn LH: Extragonadal germ cell tumors: Clinical presentation and management. Curr Opin Oncol 25: 261-265, 2013

3. Schmoll HJ: Extragonadal germ cell tumors. Ann Oncol 13: (Suppl 4) 265-272, 2002.

4. McKenney JK, Heerema-McKenney A and Rouse RV: Extragonadal germ cell tumors: A review with emphasis on pathologic features, clinical prognostic variables, and differential diagnostic considerations. Adv Anat Pathol 14: 69-92, 2007.

5. Toner GC, Geller NL, Lin SY and Bosl GJ: Extragonadal and poor risk nonseminomatous germ cell tumors. Survival and prognostic features. Cancer 67: 2049-2057, 1991.

6. Rodney AJ, Tannir NM, Siefker-Radtke AO, Liu P, Walsh GL, Millikan RE, Swisher SG, Tu SM and Pagliaro LC: Survival outcomes for men with mediastinal germ-cell tumors: The university of Texas M. D. Anderson cancer center experience. Urol Oncol 30: 879-885, 2012.

7. Talerman A: Endodermal sinus (yolk sac) tumor elements in testicular germ-cell tumors in adults: Comparison of prospective and retrospective studies. Cancer 46: 1213-1217, 1980.

8. Motzer RJ, Geller NL, Tan CC, Herr H, Morse M, Fair W, Sheinfeld J, Sogani P, Russo P and Bosl GJ: Salvage chemotherapy for patients with germ cell tumors: The memorial Sloan-Kettering cancer center experience (1979-1989). Cancer 67: 1305-1310, 1991.

9. Kondagunta GV, Bacik J, Sheinfeld J, Bajorin D, Bains M, Reich L, Deluca J, Budnick A, Ishill N, Mazumdar M, et al: Paclitaxel plus ifosfamide followed by high-dose carboplatin plus etoposide in previously treated germ cell tumors. J Clin Oncol 25: 85-90, 2007.

10. Rittiluechai K, Wilcox R, Lisle J, Everett E, Wallace HJ III and Verschraegen CF: Prognosis of hepatoid yolk sac tumor in women: What's up, Doc? Eur J Obstet Gynecol Reprod Biol 175: 25-29, 2014.

11. Shah JP, Kumar S, Bryant CS, Ali-Fehmi R, Malone JM Jr, Deppe $\mathrm{G}$ and Morris RT: A population-based analysis of 788 cases of yolk sac tumors: A comparison of males and females. Int J Cancer 123: 2671-2675, 2008.
12. Pelosi G, Petrella F, Sandri MT, Spaggiari L, Galetta D and Viale G: A primary pure yolk sac tumor of the lung exhibiting CDX-2 immunoreactivity and increased serum levels of alkaline phosphatase intestinal isoenzyme. Int J Surg Pathol 14: 247-251, 2006.

13. Zhang B, Gao S, Chen Y and Wu Y: Primary yolk sac tumor arising in the pancreas with hepatic metastasis: A case report. Korean J Radiol 11: 472-475, 2010.

14. Kumar Y, Bhatia A, Kumar V and Vaiphei K: Intrarenal pure yolk sac tumor: An extremely rare entity. Int J Surg Pathol 15: 204-206, 2007.

15. Guzel A, Tatli M, Belen D and Seckin H: Spinal cord compression of primary extragonadal giant yolk sac tumor. Spinal Cord 45: 254-257, 2007.

16. Takahashi T, Ishikawa E, Masuda Y, Yamamoto T, Sato T, Shibuya M and Matsumura A: Mixed germ cell tumor with extensive yolk sac tumor elements in the frontal lobe of an adult. Case Rep Surg 2012: 473790, 2012.

17. Ueno T, Tanaka YO, Nagata M, Tsunoda H, Anno I, Ishikawa S, Kawai K and Itai Y: Spectrum of germ cell tumors: From head to toe. Radiographics 24: 387-404, 2004.

18. Fan Z, van de Rijn M, Montgomery K and Rouse RV: Hep par 1 antibody stain for the differential diagnosis of hepatocellular carcinoma: 676 tumors tested using tissue microarrays and conventional tissue sections. Mod Pathol 16: 137-144, 2003.

19. Su JS, Chen YT, Wang RC, Wu CY, Lee SW and Lee TY: Clinicopathological characteristics in the differential diagnosis of hepatoid adenocarcinoma: A literature review. World J Gastroenterol 19: 321-327, 2013.

20. Choi HJ, Cho BC, Sohn JH, Shin SJ, Kim SH, Kim JH and Yoo NC: Brain metastases from hepatocellular carcinoma: Prognostic factors and outcome: Brain metastasis from HCC. J Neurooncol 91: 307-313, 2009.

21. Moran CA and Suster S: Hepatoid yolk sac tumors of the mediastinum: A clinicopathologic and immunohistochemical study of four cases. Am J Surg Pathol 21: 1210-1214, 1997.

22. Horie Y and Kato M: Hepatoid variant of yolk sac tumor of the testis. Pathol Int 50: 754-558, 2000.

23. Schmoll HJ, Souchon R, Krege S, Albers P, Beyer J, Kollmannsberger C, Fossa SD, Skakkebaek NE, de Wit R, Fizazi K, et al: European consensus on diagnosis and treatment of germ cell cancer: A report of the European germ cell cancer consensus group (EGCCCG). Ann Oncol 15: 1377-1399, 2004.

24. Packer RJ, Cohen BH and Cooney K: Intracranial germ cell tumors. Oncologist 5: 312-320, 2000. 